\title{
Correction to: Phytoremediation Potential of E. camaldulensis and $M$. alba for Copper, Cadmium, and Lead Absorption in Urban Areas of Faisalabad City, Pakistan
}

\author{
Ghulam Yasin ${ }^{1}$. Shafeeq Ur Rahman 2,3 (D) Muhammad Talha Bin Yousaf ${ }^{4}$. Muhammad Farooq Azhar ${ }^{5}$. \\ Din Muhammad Zahid ${ }^{5} \cdot$ Muhammad Imtiaz $^{6} \cdot$ Babar Hussain $^{7}$
}

Published online: 11 May 2021

(c) University of Tehran 2021

\section{Correction to: \\ International Journal of Environmental Research \\ https://doi.org/10.1007/s41742-021-00330-4}

The affiliation of Author's from four to seven corrected through this correction.

Original article corrected.

The original article can be found online at https://doi.org/10.1007/ s41742-021-00330-4.

Shafeeq Ur Rahman

malikshafeeq1559@gmail.com

1 Department of Forestry, Range and Wildlife Management, The Islamia University Bahawalpur, Bahawalpur, Pakistan

2 Farmland Irrigation Research Institute, Chinese Academy of Agricultural Sciences, Xinxiang 453003, China

3 Key Laboratory of High-Efficient and Safe Utilization of Agriculture Water Resources of CAAS, Xinxiang 453003, China

4 Department of Forestry and Range Management, University of Agriculture, Faisalabad, Pakistan

5 Department of Forestry and Range Management, Bahauddin Zakariya University, Multan, Punjab, Pakistan

6 Soil and Environmental Biotechnology Division, National Institute for Biotechnology and Genetic Engineering (NIBGE), Faisalabad, Pakistan

7 Institute of Agricultural Resources and Regional Planning, Chinese Academy of Agricultural Sciences, Beijing, China 